\title{
Analysis of Retaining Structure of Deep Foundation Pit in Soft Soil Stabilization of Pumping Station
}

\author{
* Yanming Chen and Wei Wu \\ Email:326697060@qq.com and 2770518936@qq.com \\ (Zhejiang University of Water Resources and Electric Power )
}

Keywords: Soft soil foundation; Deep foundation pit; Stabilization; Retaining Structure

\begin{abstract}
Pumping station is part of the construction of city infrastructure, which plays a very important role of drainage in the city. In the process of pumping station construction, its requirements for the foundation stability are very strict, especially for deep foundation in the soft soil foundation. This thus requires the deep foundation reinforcement and maintenance, which should reach the bearing capacity requirements of the structure on the foundation. Because of the complexity of the foundation pit engineering and design, improper construction, the probability of foundation pit engineering accidents is still high. Therefore, the requirements for the stability of retaining structure of deep foundation pit in soft soil must meet the requirements of structure. ${ }^{[1]}$
\end{abstract}

\section{Preface}

At present, China's large constructions are basically the design of deep foundation, the bearing capacity of deep foundation requirements will be high. The construction of infrastructure in many cities will have the problem on stability of the foundation due to the underground is mostly clay, sand soil foundation. Therefore, in order to ensure stability and safety of foundation pit and to prevent the collapse of pumping station, the construction of foundation pit excavation and timely reinforcement of the soft foundation are inevitable. ${ }^{[2]}$

\section{Engineering Examples}

Project Overview. The depth of pumping station foundation pit is 12 meters, length 40 meters, width 20 meters, along the length of each side of two rows of steel pipe pile in bracing, steel pipe pile diameter $630 \mathrm{~mm}$, inside length 27 meters, outside 19 meters, 5 meters between the inside and outside of the two rows, with the silt clay soil geology.

Pumping Station Foundation Pit Geology. According to the geotechnical investigation report, stratigraphic distribution and influence range of foundation pit excavation as the following:

(1)Miscellaneous fill clay: gray, yellowish gray, slightly wet, loose. Composition of gravel, gravel and clay, with daily and construction waste, the soil is not uniformed. Thickness: $0.2 \mathrm{~m} \sim 1.4 \mathrm{~m}$.

(2)Clay: brown gray, gray yellow clay, plastic and soft plastic, high shrinkage. With a small amount of iron manganese oxide spots or tuberculosis. Thickness: $0.4 \mathrm{~m} \sim 2.0 \mathrm{~m}$

(3)Silt: gray, green gray silt, plastic flow, high compressibility, the level of micro layered structure. Containing a small amount of fine sand, fine local shell fragments and semi-carbonized plant remains. The distribution of thickness on average is about $10 \mathrm{~m}$. The layer of soil moisture content is as high as $54.8 \%$.

(4)Mud: gray, green gray silt, plastic flow, high compressibility, the level of micro layered structure. Local fine fragments containing a small amount of shells and semi-carbonized plant remains. The distribution of thickness is about $12 \mathrm{~m}$. The layer of soil moisture content is as high as $63.5 \%$.

(5) The mud viscosity: grey, soft plastic (local plasticity), high compressibility, the level of micro layered or scaly structure. Local containing a small amount of fine sand, occasionally shell fine debris and semi-carbonized plant remains. The distribution of thickness is between $9.1 \mathrm{~m}$ and $16.8 \mathrm{~m}$. 


\section{The Excavation Pumping Station Deep Foundation}

According to the geological report, the pumping station's formation is silt clay. Since silty clay is good for dewatering, so the deep well point precipitation method should be applied. According to the formula of rectangular calculation equation, each platform bearing 6 wells, considering the island without formation of runoff and infiltration of high water level of groundwater dewatering well precipitation is not up to the requirements, setting up in the foundation at the periphery of a $1 \mathrm{~m}$ times $1 \mathrm{~m}$ ditch, a $2 \mathrm{~m}$ times $2 \mathrm{~m}$ well, a 6 inches deep well pump well point dewatering equipment along with 4 sets of 6 inch submersible pump in the foundation pit.

The excavation of deep foundation pit should combine the excavators and manpower, the foundation soil should not be disturbed. When digging near the standardized elevation about $20-30 \mathrm{~cm}$, using manpower to dig in and leveling in order to ensure the stability of ramming pipe, steel pipe, the crown beam, waist beam with mechanical excavation.ors The surplus earth should be transported manually with the crane after the excavators finish the work both at the front and back.

In the construction process, attention should be paid to the following points: the construction of foundation pit excavation slope on both sides, not pushing soil, compost. Piecewise uniform symmetrical layered excavation, follow the "hierarchical, distributed, symmetry, balance, timing" five requirements, adhere to the principles of "the construction of the vertical stratification and vertical section, rapid sealing". ${ }^{3]}$

\section{Support Structure Instability and Analysis of Its Causes}

Support Structure Instability and Performance. The entire range of periods of instability, which occurs in the bottom of the excavation to $3 \mathrm{~m}$ thick soil structure prior to the completion of the time. The main failure forms: Usually the first pile top settlement is slow, the pile top is moved outwards in the supporting structure of above phenomenon, then the basement uplifts, a tilt supporting structure, which in dozens of minutes the pile top settlement quickly drops,plus rapid uplift of basement, steel beam is twisted, most of the steel support beam is cut off. The crown, the foundation pit in the overall instability damage state.

Causes of Support Structure Instability. Instability happens where the general silt geology condition is very poor, mostly in silt and silty soil buried deep area; support structure instability happens in the majority of the time during the heavy rainfall, especially during the rainy season, continuous rainfall caused the increase of groundwater level, near the foundation pit after the water level rose more than the actual height of retaining structure of foundation pit for crown cantilever top elevation after the loss of stability, mixing with the basement uplift pile is more than $2 \mathrm{~m}$, in the upper part, outward expansion, that passive soil reinforcement strength can not meet the requirements. The fact shows that strip reinforcement as reinforcement has great influence on foundation pit point. The steel support structure supporting system of safety factor is deficient. The actual construction of steel support system has exceeded the design value of strength of steel beam, consisting of three I40b double-T steel, the support spacing is less than $3 \mathrm{~m}$. According to the monitoring data, before the collapse accidents, supporting convergence value are in line with the design requirements, but with the soil pressure outside the foundation pit increases, the active joints of the steel waling and steel support are severely damaged.

\section{Matters needing attention in Soft Soil Retaining Structure of Deep Foundation Pit Construction}

Note the time and space effect of foundation pit engineering. Pay attention to the time and space effect deformation law can not only effectively control of soft soil deep foundation pit, and if the strict construction technology applied to support and to mobilize the non-excavation section bearing capacity, coupled with the necessary foundation reinforcement, it also can achieve the purpose of 
reducing the cost, saving materials. Ensure the adjacent construction do not interfere with each other, without overloading the groundwater around the pit to take effective treatment measures. Good drainage, seepage prevention, and construction of the rainy season should be done timely in an effective way. By strengthening the detection, grasp the trend of foundation pit deformation and groundwater, and then formulate the corresponding early warning mechanism of deformation. To formulate and implement emergency measures. For foundation pit collapse, generally, there will be large deformation as the precursor, in strengthening the foundation deformation detection, if it is found that the deformation accelerated the relevant units should be promptly in accordance with plans to make the disposal measures. ${ }^{[4-6]}$

\section{Determination of Bracing Structure of Foundation Pit}

Determine the design type of support structure for building foundation pit support is an important link. The supporting structure type selection is directly related to the appropriateness of foundation pit in terms of safety reliability, technical feasibility and economic rationality. At present, with a foundation pit supporting structure are mostly single type, such as retaining structure for bored concrete pile, steel sheet pile, deep mixing pile, the underground continuous wall, high pressure jet grouting pile, soil nailing wall and so on. In the actual construction engineering, the foundation pit site, adjacent building (structure) of buildings and underground pipeline distribution, geological conditions are not the same, so sometimes taking the form of a single support structure is difficult to meet the same foundation pit engineering in different sections of the security and economic requirements. For certain parts of foundation pit, using the same structure with other parts of the supporting structure sometimes are not the best scheme. Therefore, according to the specific parts of foundation pit engineering, the choice of the type should correspond the supporting structure. Determine the basic method and principle of soft soil deep foundation pit supporting structure, selection of foundation pit retaining structure types usually must first consider the following main fields ${ }^{[7-9]}$ :

(1) The depth and scope of excavation.

(2) Excavation of the site conditions, including near the pit buildings, structures and the settlement of the ground is allowed to move to the protection object, the natural topography, the construction of outside line distance.

(3)Foundation pit engineering and hydrogeological conditions and with the progress of the works and the changing situation, especially for the soft soil in the coastal area, even in the same field area.

\section{Supporting Scheme for Deep Foundation Pit Pumping Station}

Silt of low bearing capacity, high sensitivity, high compressibility, high moisture content, careless excavation, those factors are easy to cause the collapse accidents. So for the support of the silty soil under the conditions of the foundation pit, the ideal approach is to change the fill, clay or sand, compaction after the excavation and supporting construction. If the condition does not permit and have no replacement, cement soil mixing method should be used for the silt soil reinforcement to reach a certain intensity, then continue the reconstruction of foundation pit excavation. If it is in the process of excavation of deep foundation pit, and steel pipe pile can be used with support, or reverse arch wall and other economic support.

The foundation pit excavation in soft soil foundation, and deep in depth, the initial design had considered the pile horizontal bracing, the support displacement can be controlled well, high reliability, but the cost is high, and the steel pipe piles have been used for many years. The technology has been matured. More importantly, it provides convenient to dig, and save the investment, shorten the construction period. According to the previous experience, the depth foundation pit in soft soil is generally not more than $5.5 \mathrm{~m}$, and the excavation depth is $12 \mathrm{~m}$, thus the 
steel pipe pile is feasible. It can save nearly 100,000 yuan. Pumping station deep foundation pit supporting section of the typical: horizontal tube by diameter 630 , steel thickness $10.0 \mathrm{~mm}$, length $12 \mathrm{~m}$ or $15 \mathrm{~m}$, horizontal and vertical spacing $1.2 \mathrm{~m}$, angle of 5 degrees.

Using TT350 type pipe rammer tamping close packed with $630 \mathrm{~mm}, \mathrm{t}=10 \mathrm{~mm}$ steel pipe in foundation pit, length should be $15 \mathrm{~m}$. Because of the depth of foundation pit is 9 meters, steel pipe pile in foundation pit is unstable, every 3 meters to set a waist ring beam and anchor consolidation, earthwork excavation to the waist beam $0.5 \mathrm{~m}$. Once the excavation of foundation pit in place, set the drainage ditches around the foundation pit with the precipitation.

\section{Steel Pipe Piles Construction}

Construction technique of steel pipe: pile in the pile position — point to piling machine in place — into the steel pipe pile-move to the next pile position. According to the given control points and the requirements of design drawings and the owners of the pile, put by the professional measuring personnel, and make clear signs. To be aligned with the pile location before construction, the error is less than $30 \mathrm{~mm}$, pile driving process should be slow, to ensure the verticality of pile, pile depth to the design after the stop.

\section{Steel Pipe Pile Retaining Effect}

Steel pipe piles can enhance the stability of the foundation pit. In the process of excavation, it ensures the stability of the foundation pit excavation, helping the process proceeds normally. It will not have pit collapse problems. This supporting method in deep foundation pit support is relatively common, especially in the mud geological conditions of foundation pit. Steel pipe pile retaining effect, compared with other supporting methods obviously has the advantages of economy, time saving, convenient construction.

\section{Conclusion}

Reinforcement is vital for the soft soil deep foundation pit. In the actual construction process of foundation excavation, of which support for soft foundation is the key link. At present, mainly for the silt foundation supporting with steel pipe piles, pile support, replacement method on the basis of the depth of foundation pit, which changes the support methods as well. In this foundation pit engineering, the depth is 12 meters, 40 meters long, 20 width. It is a deep foundation pit, so the stability of the foundation pit is very important. Thus using the steel pipe pile is more reasonable, because the foundation is silt geology condition. Controlling the water emission needs to handled well as well as a good foundation pit dewatering scheme in the process of reinforcement of the foundation pit. Soft soil foundation pit is very important for the safe use of the building, so in the actual construction process, for retaining structure of deep foundation pit in soft soil stabilization must attach great importance. ${ }^{[10]}$

\section{References}

[1] Yongguo Wang, Lingmin Zhang, Ming Luo, Calculation of stability of foundation pit supporting structure reliability[J];Shandong coal science and technology, 4th periodical, 2010. (In Chinese)

[2]Zhi Qin, Construction of the foundation pit supporting structure stability of engineering application analysis[J];Chinese and foreign architecture, 9th periodical, 2008.(In Chinese)

[3] Zhigang Feng, The reliability study on stability of foundation pit supporting structure[J];Guangdong building materials, 7th periodical2007. (In Chinese) 
[4] Ying Liao,The reliability study on stability of foundation pit supporting structure[J];Industrial Building, 1st periodical2004. (In Chinese)

[5] Qiujie Mou, Reliability analysis of stability of cantilever supporting structure.[J];Soil foundation, 4th periodical,2006. (In Chinese)

[6] Ying Liao, Analysis of the steady model of retaining structure of deep foundation pit stability loss of diversity[J];Journal of Suzhou University of Science and Technology (Engineering and Technology Edition), 3rd periodical 2003. (In Chinese)

[7] Shiyong Shi, Liegang Li ,Tao Liu. Retaining wall and bracing system interaction finite element analysis of deep foundation pit enclosure[J]. Chinese Journal of underground space and Engineering. 2007(02). (In Chinese)

[8] Juan Cheng. Xi'an subway station deep foundation pit construction risk management research[D]. Xi'an University Of Architecture And Technology 2011. (In Chinese)

[9] Changjiang Meng. The station hall design and monitoring of deep foundation pit of HanKou Railway Station [J]. Chinese Journal of geotechnical engineering. 2010(S1). (In Chinese)

[10] Yang Yu. Deep foundation pit support and stability analysis [D]. Liaoning Technical University 2010. (In Chinese) 